\title{
Programa Bolsa Família no Semiárido e análise dos discursos demonizadores construídos pela Igreja Católica na Paraíba
}

\section{Bolsa Família programme in the Semiarid of Paraiba ans analysis of the demonizing discourses by the Catholic Church}

Jairo Bezerra Silva - Doutor em Sociologia pela Universidade Federal da Paraíba. Professor Adjunto da Universidade Estadual da Paraíba, atuando no PPG Planejamento e Dinâmicas Territoriais no Semiárido. E-mail: jairrobezerra@hotmail.com

Lemuel Dourado Guerra - Doutor em Sociologia pela Universidade Federal de Pernambuco e pós-doutorado na Universidade de Cambridge (UK). Professor da Universidade Federal de Campina Grande. E-mail: lenksguerra@yahoo.com

Abraão Batista Costa - Mestrando do PPG em Desenvolvimento Regional da Universidade Estadual da Paraíba. E-mail: abraaobcosta@gmail.com

\section{Resumo}

O objetivo deste trabalho é analisar como se configura a ação dos discursos "demonizadores" construídos pela Igreja Católica em relação ao Programa Bolsa Família (PBF) na região semiárida da Paraíba. A metodologia é qualitativa, examinando-se discursos produzidos por representantes da Igreja Católica. Encontrouse elementos de desqualificação e condenação ao mesmo tempo em que exaltam o tradicional mecanismo de assistencialismo católico enunciado em torno do discurso da caridade. A perspectiva teórica adotada se inspira em Simmel ([1905]1998); Singer (2012; 2016) e Bello (2016). Dentre as conclusões destacamos: a) a articulação de um discurso avaliativo do PBF com efeitos negativos construídos por um ideário neoliberal, da caridade e de um assistencialismo reinventado; e b) a proposta de maior racionalização burocrática no processo de cadastramento e recadastramento das famílias a serem beneficiadas com o referido programa.

\section{Palavras-chave}

Programa Bolsa Família. Igreja Católica. Assistencialismo reinventado. Estratégias Discursivas de Eufemização.

\begin{abstract}
The objective of this work is to analyze the way in which the action of the "demonizing" discourses constructed by the Catholic Church in relation to the Family Grant Program (PBF) in the semiarid region of Paraiba State is configured. We use a qualitative methodology of analysis, examining discourses produced by Church representatives, finding in them a trace of disqualification and condemnation while extolling the traditional mechanism of Catholic assistance - enunciated around the discourse of charity. The theoretical perspective adopted is inspired in Simmel ([1905]1998); Singer (2012; 2016) and Bello (2016). Among the main conclusions of the study, we highlight: a) the articulation of an evaluative discourse of the PBF and of what the Catholic Church considers the negative effects built by the mobilization of elements of the neoliberal ideology, charity and a reinvented assistance; and b) the proposal for greater bureaucratic rationalization in the process of registering and re-registering the families to be benefited by this program.
\end{abstract}

\section{Keywords}

R'Bolsa Família' Programme. Catholic Church. Reinvented Welfarism. Discursive Strategies of Euphemization. 


\section{INTRODUÇÃO}

O processo de configuração da ação e dos discursos relativos à "caridade" pela Igreja Católica a partir do período de vigência dos programas de transferência de renda iniciados nos governos do Presidente Lula e continuados nos governos da Presidenta Dilma, afetaram de modo significativo a trajetória de vida de muitos brasileiros, especialmente os do semiárido nordestino. Por meio de pesquisas sobre a temática do Programa Bolsa Família (PBF), e fazendo uma relação desta com os "flagelos" da pobreza que testemunhamos de modo próximo enquanto sujeitos, impôs-se à necessidade de desnaturalizar discursivamente a história social na qual milhares de pessoas eram e são mergulhadas no país em geral e mais especificamente na região mencionada, integrando o que Souza (2009) conceituou como a "ralé brasileira".

Nossa inquietação com as condições de vida de muitos que compõem as chamadas 'camadas populares', vem tomando forma ao longo dos últimos anos da implementação e da capilaridade atingida pelo PBF em sua interface com a indução da mobilidade social ascendente no Brasil entre os definidos em recorrentes momentos de estiagem no semiárido nordestino como os 'flagelados da seca'.

O conjunto de nossas observações empíricas na região citada nos permitiu entender os programas governamentais de transferência de renda em geral e particularmente o PBF como uma alternativa eficiente para o enfrentamento de caráter imediato da fome, com seu conjunto de condicionamentos para entrada e saída dos beneficiários do referido programa, conforme ressaltam Singer (2012) e Bello (2016).

Para entender as dinâmicas colocadas em curso pelo PBF, mobilizamos as contribuições teóricas de Souza (2009; 2015), de Cohn (2012); de Singer (2012) e de Simmel ([1905]1998), propondo uma contraposição à tendência desqualificadora dos discursos sobre o referido programa disseminados na mídia em mesmo no meio acadêmico.

Neste trabalho, busca-se focalizar mais especificamente os discursos 'demonizadores' de representantes do clero da Igreja Católica sobre os impactos do Programa Bolsa Família na região semiárida da Paraíba, chamando a atenção sobre a reflexão que eles elaboram em torno do conceito da "caridade", resultando na produção de estigmas como o da "vagabundagem" sobre os beneficiários do referido programa, analisando falas produzidas por padres da instituição religiosa citada, atuantes na região do semiárido paraibano. 
A metodologia da pesquisa da qual este artigo é um dos resultados teve um caráter qualitativo, consistindo da constituição e análise de um corpus de discursos produzidos pela Igreja Católica na região citada sobre o PBF, a partir do qual destacamos elementos tais como o que contrapõe à ação viciadora e produtora da 'preguiça' e da 'acomodação' do referido programa na região citada, o trabalho caritativo das pastorais sociais católicas, anunciado como eficiente no sentido da superação da condição de pobreza experimentada pelos indivíduos do cariri paraibano.

Ouvimos padres, vigários, frades e senhoras católicas da 'elite' local, o que nos permitiu entender: a) o papel das paróquias em relação aos discursos 'demonizadores' para com os beneficiários do PBF na região estudada; b) os pontos convergentes e divergentes entre as ações "caritativas" da Igreja e as ações do PBF, c) e a focalização dos choques programáticos entre o que a Igreja e o PBF planejam e fazem em termos de superação da miséria com as ações que coordenam.

Analisando os discursos condenatórios da Igreja Católica sobre os efeitos do PBF, pretendemos entender em que medida os discursos elaborados e disseminados por segmentos da Igreja Católica sobre o referido programa condicionam a produção de estigmas em relação aos seus beneficiários na região semiárida da Paraíba.

\section{A GÊNESE DO PROGRAMA BOLSA FAMÍLIA}

Entre os anos de 1990 a 2015, o país articula estratégias de distribuição de renda por via de programas de transferência de recursos monetários, e de assistência social enquanto forma de enfrentamento e superação da pobreza. Nesse período, percebe-se que o esforço é vinculado ao desejo de atuar sobre as condições financeiras precárias de amplos setores da população do semiárido paraibano.

As ações estratégicas dos programas de transferências de renda implementados nos governos dos presidentes Lula e Dilma Rousseff, mais especificamente as realizadas no âmbito do PBF, mostraram resultados significativos, dentre os quais se destaca a saída do Brasil do 'Mapa Mundial da Fome' (PNUD, 2014).

O Programa Bolsa Família foi criado por medida provisória do expresidente Lula, a de $\mathrm{n}^{\circ} 132$, em 20 de outubro de 2003, para tentar corrigir o então reconhecido 'fracasso' do 'Cartão alimentação” e do Programa Fome Zero, que eram as principais alternativas adotadas por governos anteriores. O PBF é então definido como uma política pública de transferência de renda, sendo o mesmo 
vinculado a um conjunto articulado de condicionalidades contrapartísticas dos beneficiários na área da saúde, educação e assistência social (ROCHA, 2013).

De início, o programa é ligado à Presidência da República, e só em janeiro de 2004 é transferido para a Secretaria Nacional de Renda da Cidadania (SENARC), vinculada ao anteriormente denominado de Ministério do Desenvolvimento Social e Combate à Fome (MDS) (agora MDSA, Ministério do Desenvolvimento Social e Agrário). O programa propõe como suporte inicial três eixos principais: (1) proporcionar o alívio imediato da fome; (2) promover o processo de indução da melhoria dos níveis de bem-estar dos beneficiários por meio de investimentos integrados na Saúde, Educação e Assistência Social; e, por último, (3) instituir medidas capazes de viabilizar a porta de saída do programa através do ingresso no mercado formal de trabalho.

O referido programa nasce da união dos programas pré-existentes (Bolsa Escola, Bolsa Alimentação, Vale Gás e Bolsa Renda), estabelecendo uma nova lógica de racionalização dos recursos orçamentários (ROCHA, 2013; SINGER, 2012).

O cálculo do benefício a ser recebido pelas famílias que compõem o cadastro das potencialmente receptoras do PBF é complexo, baseando-se na localização dos indivíduos em faixas de renda per capita, descritas pelo MDSA como indicadoras de situações de 'extrema pobreza' (igual ou abaixo de R\$ $85,00)$ e de 'pobreza', que seria a dos que recebessem a quantia igual ou abaixo de $\mathrm{R} \$ 170,00$. Integram o referido cálculo o número de filhos com idade de 0 a 15 anos e de adolescentes entre dezesseis e dezoito anos de idade, que estejam frequentando a escola. Cada família tem direito a cadastrar até cinco filhos que estejam no primeiro intervalo, os quais recebem $\mathrm{R} \$ 41,00$ cada, mais ainda dois filhos na segunda faixa citada, recebendo cada um o valor de $\mathrm{R} \$ 48,00$.

Os valores do benefício varia, de acordo com as informações fornecidas pelo CadÚnico [Cadastro do Governo Federal usada como base de dados referente às famílias da população brasileira com renda familiar de até dois salários mínimos]. A composição do núcleo familiar, e a renda autodeclarada determinam o valor médio do benefício da família, estando tal valor sujeito aos ajustes e condicionalidades estabelecidas pelo PBF.

A título de exemplo ilustrativo, apresentamos o caso de uma família com um núcleo de nove pessoas, com cinco crianças de zero a quinze anos cadastradas, recebendo cada uma delas $R \$ 41,00$, o que totaliza $R \$ 205,00$; e com mais dois filhos adolescentes, na faixa de dezesseis a dezessete anos, matriculados regularmente em escolas, nas séries correspondentes a suas faixas etárias, cada um recebendo o Benefício Jovem Variável - BJV de $\mathrm{R} \$ 48,00$, o que somaria 
$\mathrm{R} \$$ 96,00. Acrescido ao valor básico decorrente da inclusão da família como beneficiária, que é de $\mathrm{R} \$$ 89,00, atribuído às famílias em situação de 'extrema pobreza'. Neste exemplo, quando feito o somatório geral temos: $(5 \times \mathrm{R} \$ 41,00)+$ $(2 \times \mathrm{R} \$ 48,00)+(\mathrm{R} \$ 89,00)=\mathrm{R} \$ 390,00$, que atinge o teto máximo do benefício, sendo esses valores referentes aos pagos desde julho de 2016.

De acordo com Singer (2012), O PBF objetivou, além da racionalização dos investimentos sociais governamentais, um avanço urgente em setores cuja 'tragédia social não podia esperar', com ganhos em termos de capilaridade eleitoral para o PT. Essa tese pode ser corroborada pelo fato de que mesmo os que se posicionaram contrários ao programa, atualmente no poder, são 'obrigados' a mantê-lo em funcionamento, tendo em vista a possibilidade de perda eleitoral que sua descontinuidade poderia gerar.

Segundo Souza (2016), embora o programa social seja mantido, e permaneça sendo alvo do ataque de setores neoliberais, representa menos de 0,5\% do PIB, enquanto o orçamento do judiciário brasileiro é um dos maiores do mundo, correspondendo a quase 3\% do PIB.

Essa disparidade reflete o campo de produção discursiva relativo ao PBF, no qual persistam sua 'demonização', com a recorrência da alusão ao “bando de ociosos", de "preguiçosos" que ele produziria.

Recentemente, observamos um aumento no processo de racionalização burocrática do cadastramento e recadastramento dos beneficiários. Isso tem a função de obstacularizar a entrada de novos beneficiários, intensificando uma polícia que verifica nos mínimos detalhes as experiências de 'vidas precárias', definidas por Butler (2006, p. 31), como vidas lesadas, perdidas, destruídas ou sistematicamente negligenciadas até a morte, sem que condições sociais e econômicas mínimas sejam atendidas para serem mantidas como vidas.

Os dados recentes sobre o PBF têm demonstrado uma alta relativa no índice de desligamentos, efetivados em nome do 'enxugamento' do PBF pelo governo Federal, realizados graças à 'racionalização das estratégias de controle dos beneficiários'. Essa "reformulação" pela qual vem passando o PBF é ouvida em silêncio por vários setores da sociedade, incluindo a Igreja Católica.

O desligamento dos beneficiários tem sido justificado por meio de, pelo menos, duas linhas argumentativas: a primeira, a de que os beneficiários que estão sendo desligados são aqueles de renda familiar incompatível àquela condicionada pelo programa, tendo estado nele devido à ineficiência dos sistemas de fiscalização anteriores utilizados; e a segunda, a que defende serem os desligamentos resultantes da melhoria de condições de vida dos ex-beneficiários, que teria ocorrido em função da aceleração econômica observada na sociedade brasileira. 
Quando analisada com atenção o discurso do Governo para justificar os ajustamentos dentro do PBF apresentam uma baixa plausibilidade. A alegação de que os indivíduos anteriormente potenciais beneficiários estão com rendas acima da condicionada pelo programa, é uma justificativa ideológica, já que o desempenho da economia desde 2016 não tem melhorado e as taxas de desemprego no país aumentaram. Parece mais lógico explicar a diminuição do número de beneficiários do PBF deste então pelo acirramento dos meios de vigilância das secretarias municipais, nas quais ocorre o cadastramento do PBF. Esse endurecimento na fiscalização da renda dos beneficiários chega ao ponto das secretarias enviarem assistentes sociais para fazerem averiguações nas residências das famílias vinculadas ao programa, e quando constatada a incompatibilidade entre o que os assistentes sociais veem em termos de móveis e eletrodomésticos no domicílio e a renda das famílias logo se tem o desligamento daquela família conforme apuramos em entrevista com a secretária de Assistência Social de Catolé do Rocha-PB.

A Igreja Católica, desde a implementação do PBF, tem demonstrado antipatia pelo programa, combatendo-o, desqualificando-o e reivindicando a sua reformulação ou extinção. Os ataques vêm de uma espécie de "elite clerical", como podemos perceber na carta programática da CNBB (2006) abaixo apresentado, que enxerga no referido programa fortes sinais de um caminho rumo ao assistencialismo:

A CNBB deixa clara sua posição contrária ao PBF, quando afirma por meio de Dom Aldo Pagotto, ex-presidente da Pastoral Social da CNBB e exbispo de João Pessoa, em entrevista ao jornal Folha de São Paulo em 17.11.2006, que "o dinheiro que o Governo doa às famílias de baixa renda está provocando um efeito maléfico, ou seja, está provocando acomodação nas famílias que não querem mais procurar trabalho".

O religioso ainda afirma que sua opinião é convergente com a maioria dos bispos da CNBB, e segundo a entidade, o programa em nível de Nordeste tem contribuído para uma "favelização no campo" (CNBB, 2006). Dom Aldo Pagotto, continuando a entrevista afirma ainda que o programa “[...] é só uma ajuda pessoal e familiar. É verdade que 11 milhões de famílias recebem no Nordeste e no Norte, mas isso levou a uma acomodação, a um 'empanzinamento'. Não se busca mais. Parece que não há visão de crescimento, desenvolvimento e inserção" (FOLHA DE SÃO PAULO, 18.11.2006).

O PBF teve, na região Nordeste, se compararmos agosto de 2014 com agosto de 2016 uma redução em termos numéricos de 123.935 (cento e vinte e três mil novecentos e trinta e cinco) benefícios, o equivalente a $2 \%$ a menos 
(MDSA, 2016). Sobre essa redução não encontramos nenhuma linha produzida pelos representantes da Igreja Católica no Brasil.

Em pesquisa realizada em 2017 (COSTA, 2018) acompanhamos algumas missas em diversas cidades da região do cariri paraibano. Ouvimos entre as senhoras católicas das "elites" locais que

Hoje ninguém consegue mais encontrar empregada doméstica e essas "bichas" (sic) só querem fazer meninos. Ah, mulher, encontrar alguém até pra lavar pratos é difícil. E isso foi depois do Bolsa Família. Antes você achava facilmente gente pra trabalhar. (conversa entre frequentadoras de missa, em Catolé do Rocha, PB)

Constatamos por meio das falas dos beneficiários e também nos daqueles que fazem uso do discurso clerical da Igreja Católica na referida cidade, uma teia de argumentações que apontam para o 'perigo' de um programa graças ao qual a "esmola" vai tendo seu monopólio exercido pela Igreja abalado. O discurso anti-PBF da Igreja Católica pode ser entendido pela pluralização que o programa estabelece no campo da disputa pelos 'pobres' e pelo papel de 'ajudadores' historicamente ocupado de modo central pelo catolicismo.

Com base na análise proposta por Simmel ([1905]1988), os pobres têm representado ao longo da história da cristandade um segmento da população cuja lealdade e serviço são objeto de disputas sociais entre agentes da filantropia, da caridade. O PBF teria provocado uma remodelação nos sistemas tradicionais de lealdade historicamente constituídos, abalando as posições ocupadas pela Igreja Católica, pelas elites coronelescas locais, dois grupos de agentes que passam a disputar com o Estado pelo controle da 'dádiva caritativa'.

É essa dádiva que institui, dentro da dialética simmeliana, sem resolução ${ }^{1}$, os lugares tanto dos pobres, quanto os da Igreja Católica, em seu papel de filantropia caridosa, e o dos coronéis contemporâneos, em seus papéis que ecoam os resquícios socioculturais do modo feudal de relações entre donos das terras e os peões e meeiros, figuras ainda fortes no cenário do cariri paraibano.

O PBF origina discursos 'demonizadores' produzidos pela Igreja Católica e pelas elites econômicas locais porque permite a redefinição do lugar secular ocupado pelos pobres na região em que pesquisamos, na medida em que conquistam, pelo acesso aos novos patamares de renda mínima, certa independência e níveis mais altos de autoestima, elementos cruciais na desestruturação das 'economias da caridade e da servidão' tradicionais, nas quais são protagonistas tradicionais os atores citados acima.

O que a diferencia da 'marxista', que prevê resoluções sintéticas. 


\section{ALGUNS PARÂMETROS AVALIATIVOS DO PROGRAMA BOLSA FAMÍLIA}

O PBF tonou-se, ao longo de sua primeira década de existência, uma referência no que tange à segurança alimentar, ao ponto de servir de modelo recomendado pelo Fundo Monetário Internacional (FMI), a ser adotado por países em desenvolvimento e com problemas de distribuição de renda, contribuindo para que o Brasil ficasse reconhecido no cenário internacional como um ícone no que tange às medidas eficazes no combate à fome (PNUD, 2014; IPEA, 2013).

Conforme os relatórios de instituições globais e locais citados, bem como o da FAO (2014), entidade que há cinquenta anos vem fazendo um acompanhamento sistemático da fome no mundo, o problema da subalimentação no Brasil atinge a menos de 5\% da população brasileira, indicando que o país conseguiu 'sair' do mapa da fome no mundo.

Segundo o IPEA (2013), entre os anos de 2001 e 2012, os 20\% mais pobres no Brasil tiveram sua renda elevada proporcionalmente três vezes mais que a renda dos $20 \%$ mais ricos. Esses estudos ainda comprovam que a taxa de pobreza extrema, do ano de 1990 a 2012, foi reduzida de 25,5\% para 3,5\% no Brasil; na região Nordeste esse número decresceu de $28,4 \%$ para $4,3 \%$ no período citado.

A mensuração e o conceito de indigência de um País é algo que requer certa complexidade analítica. De acordo com Sales (2015), esses conceitos representam um conjunto histórico de avaliações que se desdobram dialeticamente. Algumas nações, a exemplo de Portugal e Estados Unidos da América (EUA) têm feito uso de parâmetros financeiros para delimitar aquilo que se caracteriza como as categorias de pobre e indigente. O Brasil é um dos países que aceitaram a divisão monetária entre as linhas da pobreza e extrema pobreza, classificando de pobre, segundo o MDSA (2016) os que têm uma renda mensal igual ou inferior a $\mathrm{R} \$ 178$ e de 'extremamente pobres', os que percebem a renda mensal de até $\mathrm{R} \$ 89,00$.

Bello (2016) nos mostra as assimetrias entre o valor das linhas de pobreza e extrema pobreza quando das utilizadas pelo PBF que tem em sua matriz vinculada à orientação do Banco Mundial (US\$1,25 diário), e as linhas adotadas pelo índice oficial do custo de vida (IPCA) - de R \$194,80 (extrema pobreza) e de $\mathrm{R} \$ 509,00$ (pobreza). Quando comparadas os tetos das categorias de pobreza citadas adotadas pelo PBF, observamos que os valores referentes a este é 2,3 vezes menor quando se trata da linha da indigência (extrema pobreza) e 3,0 vezes menor quando se refere à linha da pobreza medida pelo IPCA (BELLO, 2016). 
Para ter uma noção comparativa dos sentidos da pobreza e relativizar a decisão de transferir renda para os mais pobres no Brasil, Sales (2015) nos apresenta essas mesmas linhas, mas em diferentes países. Em Portugal, por exemplo, é considerado 'pobre' o indivíduo que tem renda mensal igual ou abaixo de \$ 421 euros, cerca de $\mathrm{R} \$ 2.000,00$ (cotação média em setembro de 2018). Nos EUA, país que adota muitos critérios para a determinação da pobreza, mas todos com base nos aspectos financeiros, segundo a autora citada o indivíduo que ganha igual ou abaixo de US\$ 975 mensais é considerado 'pobre', e se esse valor da renda mensal do cidadão americano atingir apenas 50\% dessa cifra, ele é caracterizado como em 'pobreza aguda'. Em relação a Portugal, a linha da pobreza lá 8,3 vezes mais alta que a do Brasil. Quando se trata dos EUA, vemos que a sua linha de pobreza é 18,18 vezes mais alta que a do Brasil (SALES, 2015).

A forma como são pagos os vencimentos do benefício do PBF (eletronicamente), seguindo um calendário oficial, em certa medida dispensa a ajuda de terceiros, contribuindo para manter os beneficiários relativamente "afastados" do tradicional clientelismo regional/local, liberando-os da forte cultura do favor presente na região do cariri paraibano.

O PBF completará em outubro de 2018, quinze anos de existência no Brasil. Durante esse tempo o programa passa a viver também a experiência da globalização, ou seja, por ser reconhecido pela ONU (2011) como sendo um dos principais programas de combate e superação à pobreza do mundo, o PBF passa a ser citado internacionalmente como um bom exemplo de erradicação da miséria. $\mathrm{E}$ isso o habilita para ser copiado por vários países, invertendo, como ressalta Cohn (2012), o caráter desqualificador do alinhamento inicial do programa à ideologia do Banco Mundial.

Os dados sobre os que saíram do PBF (MDSA, 2016) mostram um significativo aumento no número dos que não se enquadram mais nos requisitos de renda mínimos. Evidentemente para a interpretação desses dados é preciso considerar o montante daqueles que efetivamente saíram, por terem atingido renadas mais altas e o montante dos que recebiam indevidamente, pela ineficiência do acompanhamento das condicionalidades previstas no programa.

Para se calcular os números dos egressos do PBF é necessário que usemos uma fórmula matemática, e na mesma, de posse dos números disponibilizados no CadÚnico $^{2}$ com as respectivas faixas de rendas per capitas condicionais para o benefício, o cálculo se torna algo simplificado.

4.Cadastro Único para Programas Sociais do Governo Federal é um instrumento que identifica e caracteriza as famílias de baixa renda, entendidas como aquelas que têm renda mensal de até meio salário mínimo por pessoa, ou renda total mensal de até três salários mínimos (MDS, 2016). 
Exemplificando na equação: $\left(\mathrm{B}_{1}+\mathrm{B}_{2}\right)-\mathrm{NTB}_{\mathrm{PBF}}=$ egressos do PBF. Onde: $\mathrm{B}_{1}$ é o número de famílias com renda per capita de $\mathrm{R} \$ 0$ até $\mathrm{R} \$ 89,00$;

$\mathrm{B}_{2}$ é o número de famílias com renda per capita que varia de $\mathrm{R} \$ 89,01$ até $\mathrm{R} \$ 178,00$;

$\mathrm{NTB}_{\mathrm{PBF}}$ é o número total de famílias que recebem o benefício do PBF.

Assim, de acordo com o MDS (Set/2016), o CadÚnico conta em suas bases de dados com 27.160.008 milhões de famílias inscritas, sendo que desse número 12.707.404 milhões de famílias têm renda per capita até $\mathrm{R} \$ 85,00$; 4.152.311 milhões de famílias com renda per capita que varia de R\$85,01 e R\$ 170,00; 6.179.281 de famílias com renda per capita familiar entre R\$170,01 e meio salário mínimo e 4.121.012 de famílias com renda per capita acima de meio salário mínimo. Ao mesmo tempo em que no citado período o número total de beneficiários do PBF foi de 13.884.050 famílias³ .

Assim, quando trazemos os números para a equação temos: $\left(\mathrm{B}_{1}+\mathrm{B}_{2}\right)-$ $\mathrm{NTB}_{\mathrm{PBF}}=$ egressos do PBF. Transformando, temos: $(12.236 .939+4.036 .194)$ - 13.847.958 = 2.425.175 milhões de famílias que não recebem o benefício do $\mathrm{PBF}$, apesar de estarem dentro das condicionalidades exigidas pelo programa em Mai/2016, ou seja, os excluídos do PBF.

Quando averiguamos os mesmos números, sendo que dessa vez utilizando os dados fornecidos pelo MDS (Dez/2014), percebemos que a cifra referente aos excluídos do PBF cai consideravelmente. Em dez/2014, o CadÚnico tinha em seus registros 14.095 .333 milhões de famílias com renda per capita de R\$ 77,00; 5.525 .302 milhões de famílias com renda per capita que varia de $\mathrm{R} \$ 77,00$ e $\mathrm{R} \$ 154,00$. Nesse mesmo período, o número de beneficiário do PBF foi de 14.003.441 milhões de famílias.

Assim temos: $\left(\mathrm{B}_{1}+\mathrm{B}_{2}\right)-\mathrm{NTB}_{\mathrm{PBF}}=$ excluídos do PBF. Transformando: $(14.095 .333+5.525 .302)$-- 14.003.441 = $\mathbf{5 . 6 1 7 . 1 9 4}$ de famílias que não recebiam o benefício do PBF em dez/2014, ou seja, os egressos do PBF. Quando comparamos com os números de dez/2014 aos de mai/2016, averiguamos uma redução em termos numéricos de $(5.617 .194$ - 2.425.175) $=\mathbf{3 . 1 9 2 . 0 1 9}$ milhões de famílias que ingressaram no programa e, consequentemente, esses números decrescem os excluídos do PBF. E, em números percentuais isso significa uma queda de 57,4\% no Brasil (CÁLCULOS DOS AUTORES).

O exército de saída é a quantidade de famílias que conseguem sair do programa pelo fato e declararem rendas superiores às estipuladas pelo PBF, e pelas análises dos números, observou-se que essas famílias saem em maior número da faixa da pobreza (renda de $\mathrm{R} \$ 85,00$ até $\mathrm{R} \$ 170,00$ ) 39,8\%, enquanto

3 Apenas as famílias com renda per capita de $\mathrm{R} \$$ de $\mathrm{R} \$ 85$ até $\mathrm{R} \$ 170$ entram neste cálculo. 
que da faixa da extrema pobreza esse número atinge apenas 6,0\%. Quando levamos a questão a nível federal, constatamos através dos dados do MDS que também a faixa com maior número de famílias que conseguem atingir o exército de saída vem da pobreza ${ }^{4} 16,67 \%$, contra 7,5\% da extrema pobreza ${ }^{5}$.

\section{OS MITOS DA OCIOSIDADE, PREGUIÇA E DAS 'MULHERES PARIDEIRAS'}

Quando se analisa com profundidade os Programas de Transferência de Renda (PTR) e seus mais variados impactos, observa-se em relação ao PBF discursos estigmatizantes que surge dos mais variados atores sociais contra os beneficiários. Adjetivos que aparecem nos discursos cotidianos para qualificar as pessoas que têm vínculos com o programa são, por exemplo: acomodados, preguiçosos, ociosos, sanguessugas, parasitas, viciados, parideiras. Eles contrastam com pesquisas que atestam a eficácia do programa diante de seus objetivos. Oliveira e Soares (2012) são autores que desconstroem a tese da ociosidade que o PBF produziria, mostrando que as pessoas incluídas no programa têm maiores chances de participação no mercado de trabalho que aqueles que estão desvinculados dele.

Vários são os preconceitos atribuídos às famílias beneficiárias. Um dos mais comuns é a culpabilidade pela sua condição de pobre e assistido, visão que se "casa" com o discurso da meritocracia forjado no seio das desigualdades socioeconômicas. Ramacciotti (2014) mostra que parte dos beneficiários internaliza o discurso que os responsabiliza pelo fato da pobreza se originar do não cumprimento das condicionalidades. De certa forma, essa culpa recai mais sobre as mulheres por serem elas em grande maioria as titulares do benefício e responsáveis por estarem em contato mais direto com seus filhos.

Observamos que os beneficiários são penalizados duas vezes, pois além da pobreza, recebem a culpa por serem pobres. Discordando desse estigma, a autora diz que "a premissa de que pais mais pobres de alguma forma são culpados se seus filhos não vão à escola ou ao médico, é inconsistente com as explicações estruturais da pobreza" (RAMACCIOTTI, 2014, p. 102).

Em um estudo que avalia o trabalho do assistente social no acompanhamento às condicionalidades do PBF, Carnelossi (2016) levanta a questão das matrizes ideológicas do programa, ou seja, a relação do pacto existente entre Estado

5. São as famílias cadastradas no CadÚnico com renda mensal per capita que varia de $\mathrm{R} \$ 85,00$ a $\mathrm{R} \$ 170,00$ segundo o (MDS, 2016).

6. São as famílias cadastradas no CadÚnico com renda mensal per capita que varia de $\mathrm{R} \$ 00,00$ a $\mathrm{R} \$ 85,00$ segundo o (MDS, 2016). 
de um lado e o beneficiário do outro, a institucionalização que dá ao Estado o direito de comando, e do outro a de ser comandado (os beneficiários). Segundo a autora, essa relação de controle requer penalizações em casos de desobediências e fraudes, o que faz com que o profissional da área de assistência social venha a se precaver contra certa generalização de estigmas recorrentes aos beneficiários. A autora reforça que "o profissional se depara com o desafio de resistir às atribuições que reforçam práticas conservadoras de auto responsabilização das famílias por sua condição de pobreza" (CARNELOSSI, 2016, p. 144).

Achar que todas as famílias beneficiárias vivem apenas do benefício do PBF indica a falta de conhecimento do programa e mais ainda do contexto diário das famílias a eles vinculadas. Há assimetria entre não querer trabalhar e trabalhar por 'qualquer coisa'. Quem conhece a vivência dos beneficiários percebe cotidianamente suas ações para saírem da situação de pobreza na qual estão inseridos. Achar que uma família pode viver apenas com a renda do PBF, como mostra Medeiros, Britto e Soares (2007, p. 15) é algo imaginável.

Ainda sobre a relação entre o PBF e a atitude em relação ao trabalho, Prosperi e Frias (2016) constataram que o programa influencia as famílias a adentrarem no mundo do trabalho, e essa 'força' que é oferecida às famílias passa em grande parte pela educação como é o caso do PRONATEC. Assim, os autores observaram que além da promoção ao suporte alimentar, o PBF promoveria uma relativa autonomia. Nas palavras deles:

As iniciativas de inserção laboral do BSM, juntamente com as garantias do PBF que protegem a família beneficiária que tem inserção laboral ou se desliga voluntariamente, promovem segurança e incentivo para a busca da autonomia financeira das famílias. Esses são esforços para garantir que a participação das pessoas mais pobres no mercado de trabalho se expanda ainda mais, desde que feita de maneira adequada e sustentável. Asseguradas e apoiadas, as famílias pobres passam a ter acesso à formação profissional, serviços de intermediação de mão de obra, estímulo ao empreendedorismo, ações de economia solidária, crédito facilitado e poderão finalmente se sentir empoderadas (PROSPERI; FRIAS, 2016, p.192).

A acomodação dos beneficiários tem sido, durante esses 13 (treze) anos de implementação do PBF, uma das críticas mais recorrentes ao programa. Frequentemente, a mídia atribui por meios de televisão, jornais, blogs etc. o estímulo à ociosidade, enfatizando esse como sendo um dos pontos negativos dessa política pública de distribuição de renda.

Silva et al. (2016), ao estudarem o estigma da 'vagabundagem', perceberam um baixo índice de pessoas que preferem a bolsa ao invés de um emprego formalizado, mesmo diante das incertezas do mercado formal de trabalho para 
pessoas com pouca escolarização e baixa qualificação, como é o caso da maioria dos beneficiários do PBF. Nas palavras dos autores: "Encontramos um baixo número de pessoas que preferem o Bolsa Família ao trabalho formal, apesar do medo da instabilidade que o mercado de trabalho pode trazer e isso pode acarretar em perda do benefício para as famílias do programa” (SILVA et al., 2016, p.260).

Para Foguel e Barros (2010), que fizeram um acompanhamento entre 2001 e 2005 buscando analisar a quantidades de horas trabalhadas por beneficiárias do PBF em 806 municípios brasileiro, programas de transferência de renda como o PBF não reduzem significativamente a participação das mulheres no mercado de trabalho, seja na amostra de forma geral, ou na faixa que compreende as $50 \%$ mais pobres.

Ribas e Soares (2011) analisaram o efeito dos impactos do PBF no trabalho das mulheres observando as peculiaridades geográficas. Os autores observaram um aumento do trabalho feminino no meio rural e na informalidade, considerando as baixas necessidades de qualificação que esse setor exige de seus empregados.

Diversos outros resultados apresentados na vasta literatura que estuda a temática do PBF vêm mostrando a fragilidade da argumentação sobre seu pretenso efeito da ociosidade entre seus beneficiários, destacando os aspectos positivos do programa em relação ao trabalho. Oliveira e Soares (2013) dizem que esses resultados variam em função do tempo e do método utilizado, mas mostram que há uma associação entre o PBF e a redução da oferta de trabalho quando se trata de trabalho infantil. Nas palavras deles:

Os resultados encontrados pela literatura, até o momento, variam um pouco ao longo do tempo e de acordo com o método. Entretanto, apontam para um consenso de que programas de transferência de renda são eficazes em reduzir a oferta de trabalho das crianças, reduzindo também o número de crianças que não estudam e não trabalham (OLIVEIRA; SOARES, 2013, p. 355).

Esses autores seguem mostrando que os impactos negativos do PBF sobre o mercado de trabalho são de baixo alcance:

[...] os PTRCs possuem impactos pequenos sobre o mercado de trabalho. Alguns destes impactos, como a redução da jornada de trabalho das mães e o aumento na probabilidade de trabalho para certos grupos, são positivos. Do ponto de vista das políticas públicas, pode-se afirmar, com muito embasamento, que não existe constatação empírica que sustente a hipótese de que haveria um efeito renda maior do que um efeito substituição (fenômeno que recebeu a alcunha de "efeito preguiça"), no caso destes programas (OLIVEIRA; SOARES, idem, p. 356). 
Além do estigma de 'preguiçosos', também se fazem recorrentes várias outras denominações com sentidos desqualificadores. Constantemente, a palavra parideira tem sido atribuída às beneficiárias, alegando-se que o PBF é um incentivo para que as mulheres tenham mais filhos, já que o valor do benefício está condicionado ao número de filhos do núcleo familiar (Cf. COSTA, 2015).

Essa alegação vai contra os recentes dados do IBGE (2010) sobre a taxa de fecundidade da mulher brasileira, segundo os quais ela manteve a forte tendência de queda, começando a década de 1970 com a média de 5,8 e chegando à de 1,9 filhos por mulher em 2010, podendo atingir 1,5 em 2034, fato que ocasionará um encolhimento populacional como mostra o IBGE (2010). Pela primeira vez no Brasil esse índice fica abaixo da taxa de reposição populacional, que, segundo a estatística desse instituto seria de 2,1 filhos por mulher, sendo "as maiores quedas em relação aos números nacionais observadas nas regiões Nordeste e no Norte: 23,4\% e 21,8\%, respectivamente" (IBGE, 2010).

A taxa de fecundidade brasileira foi historicamente mais alta entre as camadas sociais mais pauperizadas, a argumentação de que as beneficiárias irão se tornar mais parideiras, por isso representar o aumento no valor do benefício indica a circulação e disseminação de um senso comum interessado. A falta de informações e de acesso aos métodos contraceptivos sempre foi característica predominante das classes pobres brasileiras. O número de filhos por mulher não aumenta em função do benefício do PBF, mas sim, ele sempre existiu para os mais pobres. É o que argumentam Ales \& Cavendish, nos seguintes termos:

A fecundidade mais elevada entre a população pobre, menos escolarizada, com menor nível de consumo e piores condições habitacionais é uma realidade constatada em todas as pesquisas sobre o comportamento reprodutivo no Brasil. A literatura mostra que, em grande parte, esta maior fecundidade se deve à falta de acesso aos serviços de saúde sexual e reprodutiva, mas também acontece devido à falta de perspectivas profissionais e educacionais, assim como de um projeto de vida que possibilite o progresso cultural e material destas mulheres jovens (ALVES; CAVENAGHI, 2013, p. 236).

Vários estudos têm mostrado que a taxa de fecundidade vêm passando por uma fase transitória, e que esse fenômeno não é mais característico apenas das classes abastadas. São várias as evidências empíricas mostrando que:

Esta transição não é um fenômeno exclusivo da população rica. A geração mais velha, formada pelas mães das mulheres entrevistadas, teve um número de filhos bem superior à geração atual: quase $80,0 \%$ tiveram quatro ou mais filhos e foi praticamente zero a porcentagem de mulheres sem filhos. Já para a geração atual, formada por todas as mulheres que 
responderam à pesquisa, somente $17,9 \%$ tiveram quatro ou mais filhos, $21,8 \%$ tiveram três filhos e a porcentagem maior $(37,1 \%)$ ficou para as mulheres que tiveram dois filhos. A porcentagem com um filho ficou em 21,6\%, e as sem filhos, com 1,5\% (ALVES; CAVENAGHI, 2013, p. 237).

Como vemos acima, os números mostram que no período entre 2001 e 2013 a pobreza no país esteve com seus índices em redução. Para entender a complexidade da pobreza em suas múltiplas dimensões também recorremos a Ivo (2008) em sua análise da obra de Simmel intitulada 'Les pauvres' ([1905]1998), chamando a atenção para o que o autor apresenta como sendo relações intersubjetivas da 'obrigação da dádiva', mostrando as relações entre a ética, a moral e a sociedade, na construção da dádiva e da caridade. A autora citada propõe que entendamos a pobreza como algo abstrato, e que a estrutura da dádiva aos pobres funciona como mecanismo regulatório, contribuindo para 'amortecer' os 'perigos' que a insatisfação das camadas pobres da população pode representar para a 'ordem e harmonia social'.

É graças a essa funcionalidade da lógica "caritativa" e da "dedicação ao próximo' que a ideia e práticas do voluntariado, inspiradas na filosofia neoliberal de fundo assistencialista, ganha força. De modo mais ou menos explícito e consciente setores da Igreja Católica no Brasil e especificamente no semiárido paraibano ganha plausibilidade, combatendo o PBF por produzir para seus formuladores eventuais gradações de dependência e lealdade dos beneficiários, reações anteriormente desenvolvidas em relação à Igreja filantropa.

Com o PBF, são colocadas em outro patamar de importância ações como as desenvolvidas há anos pela Pastoral da Criança junto às camadas com maior vulnerabilidade social, no acompanhamento das gestantes, dos partos e das crianças de zero a seis anos de idade, em cujo âmbito era divulgado o sucesso de a multimistura, uma receita alimentar que combinava o uso de sementes, cascas de frutas e de algumas verduras ricas em proteínas e sais minerais essenciais ao organismo das crianças em fase de crescimento; a eficácia do uso do soro caseiro, uma mistura à base de água, açúcar e sal como principal 'ferramenta' capaz de inibir os altos índices de desidratação, na época definidos como o principal "vilão" da mortalidade infantil (MARQUIORO; FIORENTIN, 2012).

Com base nas reflexões de Simmel (1998) sobre a forma social 'os pobres', analisamos a formulação de discursos 'demonizadores' do PBF por parte da Igreja Católica a partir do que ele chamou de quebra da "obrigação socializada" mediada pelo referido programa. A partir do recebimento do benefício do PBF nos termos de uma renda mínima, as práticas 'de dar' exercidas pela Igreja, que não se derivavam do reconhecimento do direito do outro, mas da construção 
de uma figura relativa à qualidade moral dos doadores, passa por um processo de desestruturação simbólica. O ganho de reconhecimento e em termos de autoimagem da Igreja é abalado, na media em que os indivíduos se empoderam pela posse do cartão do PBF como um protocolo de acesso a níveis mínimos de consumo que os retiram do campo de ação da dádiva filantrópica, liberando-os da imposição moral daquele que dá.

O PBF coloca em cheque o 'mercado dos necessitados' em cujo âmbito a Igreja Católica milenarmente se legitimou. É a partir da desestruturação da relação de dualidade construída em torno da "dádiva" que é feita e estabeleceria a contrapartida do reconhecimento da superioridade moral daquele que doa que interpretamos a produção de discursos desqualificadores do PBF produzidos pela Igreja.

O programa aqui focalizado representa modificações na arena dos atores que disputam o campo dos necessitados: o Estado procura assumir uma postura de que "enxerga" sua responsabilidade diante das condições de vida da população cujos interesses deveria proteger, ocupando o espaço antes preenchido pelas obras de caridade dos "bons senhores", dentre os quais se destacava Igreja; b) a Igreja Católica precisa enfrentar a diminuição do segmento populacional que se constituía como finalidade das suas ações de caridade e filantropia, o que lhe coloca a necessidade de redefinição institucional em sua relação com a sociedade.

\section{OS DISCURSOS SOBRE O PBF PRODUZIDOS POR CLÉRIGOS DA IGREJA CATÓLICA}

Os discursos clericais sobre os efeitos do PBF apontam para um ressentimento velado em relação às mudanças trazidas. Vejamos alguns exemplos:

Nós da Igreja temos a força de mobilizar pessoas para que nos ajudem a ajudar os mais pobres e necessitados. Não buscamos nada em troca, fazemos pelo amor ao próximo promulgado por Cristo em nossos corações. Fazemos campanhas, pedimos contribuições no comércio. E sempre temos êxito, porque mostramos para onde vai a oferta dada por eles. Prestamos contas à Igreja, aos que contribuem e à população. Tudo o que arrecadamos e damos, expomos no mural da Igreja. Vejo o Bolsa Família, com bons olhos. Ajuda os pobres. Porém, podia ser melhor. O valor é pouco, não tem o mesmo nome, mas é uma esmola também. E vejo um interesse político que começa no município. Colocam as pessoas que querem, dão a quem não precisa e dificulta a quem não é do partido de quem está no poder. É como eu já disse. É um ótimo programa, tem uma grande contribuição, pois tudo que é ofertado a quem precisa é bom. Porém, falta gestão e honestidade. (DIÁCONO DE UMA DAS IGREJAS DA REGIÃO SEMIÁRIDA PARAIBANA, MARÇO, 2017). 
O que identificamos na fala do diácono é que ela começa com um comentário sobre a honestidade e a integridade da Igreja e termina com a alusão à desonestidade do sistema de gestão do PBF. Pode ser vista a articulação da estratégia discursiva, segundo a qual se comparam agentes que operariam a 'economia das esmolas', construindo-se uma autoidealização da Igreja e uma desqualificação do Estado. O conflito é entre os atores que desejam protagonizar as dinâmicas da 'economia dos necessitados'.

Vejamos outro exemplo de discurso produzido no âmbito da Igreja, desta feita, pelo representante do grupo de oração denominado 'Terço dos Homens', que coordena o setor de trabalhos de caridade em uma das paróquias do semiárido paraibano:

Tem muito pobre que precisa. Só acho que o PBF deveria ser mais fiscalizado. Por exemplo, ajudamos tanto pobre que é pobre de verdade, que não tem o que comer e não recebe o beneficio. Eu acho que o governo devia ver uma saída pra isso. Fazer uma parceria com quem realmente está preocupado com o pobre. Sem interesse. Como, por exemplo, essas ONGs que faz caridade, as igrejas, todas elas. Porque por exemplo, a Igreja sabe onde estão os pobres, porque os necessitados procuram Deus e a Igreja, em busca de ajuda e oração. Eu acho que devia ser feito assim. Político hoje não ajuda pobre, só eles mesmos. (REPRESENTANTE DO TERÇO DOS HOMENS, MARÇO, 2017).

O mote inicial é a necessidade intensificar a fiscalização, medida que contribuiria para que o PBF ajudasse os 'pobres de verdade'. Interessante é a proposta que aparece na fala de uma parceria entre o Estado e ONG e com a Igreja. O argumento é de que a instituição 'sabe onde estão os pobres', o que significa as autorização e uma desautorização velada do Estado, que não seria tão competente em detectar os que realmente precisam do benefício. Vale também destacar a eficiência do apelo midiático que age 'quase' como um imperativo para que se fale e se pense em termos da necessidade de aumentar a vigilância sobre os beneficiários. O que a propaganda estatal vem sugerindo é que os próprios beneficiários exerçam a função de vigiar seus semelhantes, o que pode ter o efeito de internalização de um conjunto de práticas coercitivas.

$\mathrm{Na}$ fala de um padre que apresentamos a seguir podemos perceber como a explicação da pobreza ganha contornos espirituais e religiosos, o que implica na desautorização da busca de soluções políticas para as desigualdades sociais. Vejamos:

Irmãos, Jesus nos ensina a amar o próximo, a partilha, a fazer caridade, a fazer nosso semelhante feliz. Assim como Maria, devemos confiar em Cristo, pois aquele que está em Cristo não padece. Aquele pobre que está 
jogado lá nas ruas, com fome, sem uma casa, no mundo das drogas, se estivesse em Cristo, não estariam padecendo, se eles buscassem a palavra de Deus e o amor em Cristo e Maria, não estariam ali. E o que devemos fazer? Restaurar o nosso irmão. Partilhar. Partilhar o alimento, nossas roupas e acolher em nosso coração. $\mathrm{O}$ nosso irmão que está padecendo, é responsabilidade nossa enquanto Cristão, enquanto Igreja. Deus fica triste quando o filho seu está sofrendo. E fica mais triste ainda quando um filho seu não ajuda um irmão. Partilhai o pão de Cristo. (PÁROCO DE UMA DAS IGREJAS DA REGIÃO SEMIÁRIDA PARAIBANA, ABRIL, 2017)

A definição das causas da existência dos pobres, dos necessitados em termos espirituais aponta para uma "barreira programática" erguida por setores da Igreja no sentido da busca de soluções políticas para a questão da pobreza e da vida precária na região do semiárido paraibano. Os termos de descrição da causalidade espiritual do fenômeno da pobreza se desdobram no apelo para a posição da partilha, da caridade da solidariedade prestada em termos de assistência social, o que afasta as populações de pensarem em ações e projetos estruturantes de mobilidade social que incentivem a ruptura das relações de assujeitamento e dependência nos seus diferentes níveis, inclusive aquela produzida pela Igreja caridosa e filantrópica.

$\mathrm{Na}$ fala de outro padre da mesma região em que fizemos a pesquisa é muito emblemática a alusão ao 'governo de Cristo' e ao sentido do 'doar aos pobres':

Estamos vivendo um momento de turbulência, com escassez de chuvas e crise de governança. E esse é um momento crucial para refletirmos sobre Jesus, o maior líder que já existiu, que governou com maestria todo o seu povo. E por que o governo de Cristo deu certo? E continua dando certo? Porque ele governa com o coração, buscando o bem-estar do próximo, porque o governo de Deus é pautado no amor, na humildade, na caridade. Ele vê o pobre como filho, e se sente inquietado com o sofrimento destes. E Maria misericordiosa, mãe de Deus, doce ternura, o auxilia. Sejamos sempre misericordiosos, sejamos solidários, contribuamos com as campanhas de caridade, façam doações, ações de amor ao próximo, façamos parte todos nós da Igreja, a Igreja que acolhe a todos, que não vê raça, partido ou cor. Se Jesus é o nosso líder, como de fato é. A igreja é o palácio de Deus, onde ele dá as instruções para o seus servos. Vamos compor esse governo de Deus, onde não há crise, não há problemas de gestão e nenhuma forma de exclusão. (II PÁROCO DE UMA DAS IGREJAS DA REGIÃO SEMIÁRIDA PARAIBANA, ABRIL, 2017).

A fala do pároco, embora embargada de emoção, não esconde a necessidade da existência do pobre, o interesse eufemizado pela manutenção do status quo da 
caridade, para que a "bondade" de parte da sociedade tenha condições de se plausibilizar. O fato de o PBF vir a contribuir para o rareamento da miséria tira da Igreja um público que outrora pertenceu ao seu universo caritativo, e, assim, aquilo que é um direito social e humano, ou seja, o direito à alimentação básica, um dos pilares do PBF, passa a ser visto com 'maus olhos' por alguns setores da hierarquia da igreja e dos fiéis.

As críticas veladas aos governos dos homens, colocados implicitamente como o oposto do 'governo de Cristo', no qual não haveria exclusão, crise ou nenhum problema de gestão’ - em uma alusão eufemística ao problema de corrupção, um tema caro dos que desejam de certo modo desautorizar a política, em favor dos que querem exercer o poder político explicam a posição de 'demonização' do PBF adotada por setores da Igreja Católica, dentre outros detratores do referido programa. O trecho final da fala citada é claro em termos da indicação de alternativas para a solução dos problemas da pobreza e da vida precária em nossa sociedade: apela-se à caridade.

Para que a caridade exista é preciso que se garanta o mercado dos que dela necessitam. Nossa interpretação dos discursos da Igreja sobre o PBF é a de que ele coloca sob tensão, pela relativa monetarização dos seus beneficiários, a economia dos necessitados, contribuindo para o rareamento dos que têm composto historicamente o público alvo das obras 'caritativas' dos católicos e religiosos em geral.

\section{CONSIDERAÇÕES FINAIS}

Neste trabalho procuramos interpretar a produção dos discursos da Igreja Católica sobre o PBF, apontando para algumas dimensões da 'economia da caridade' a partir das reflexões simmelianas sobre a forma social recorrente em várias sociedades, 'os pobres' em sua propriedade de constituir-se a si mesma e aos 'doadores', 'caridosos', 'filantropos'.

A partir da análise de discursos produzidos por representantes dessa instituição, pretendemos apontar para as bases objetivas da mobilização de símbolos nos discursos produzidos por representantes institucionais e fiéis comuns sobre o programa aqui focalizado. Em termos de reprodução institucional é mais cômodo no atual cenário do campo religioso nacional para a Igreja que não se altere o mercado/campo de pobres, o que possibilita a atualização de sua identidade baseada nos elementos milenarmente exercitados da 'caridade' e da 'ajuda', com os ganhos em termos de reciprocidade que o mecanismo da dádiva estabelece, realizando projetos articulados ao ideário neoliberal, caritativo, 
assistencialista e voluntarioso dos irmãos, partilhados com empresários, grandes comerciantes e fazendeiros do que assumir a defesa de um projeto relacionado com a produção da autonomia, com um caráter de ação coletiva.

De acordo com a visão de Simmel ([1905]1998) que vê os fenômenos sociais como constituídos de forma dialética, no sentido de que os termos antitéticos se constituem mutuamente, o PBF, ao alterar o polo dos pobres/ necessitados, provocam instabilidade no polo dos caridosos, dos solidários, dos bondosos, alterando o status identitário da Igreja Católica.

Diante da reconfiguração do contexto de 'vida precária' e de necessidade das populações rurais no cariri/sertão paraibano, emergem estratégias de readequações discursivas da 'caridade' pela Igreja Católica, como forma de enfrentamento da pobreza, num contexto em que o Programa Bolsa Família se consolida como sendo capaz de induzir mobilidade social ascendente e níveis crescentes de empoderamento e autonomia das camadas populares da população brasileira.

A proposta de estabelecimento de parcerias entre a Igreja Católica e o Estado no atendimento aos 'pobres' pode contribuir para a compreensão do silêncio da instituição observado na região de semiárido em relação à recente eliminação de um número significativo dos beneficiários, e a configuração de discursos dos clérigos e líderes leigos católicos no sentido da disseminação do estigma da produção de 'sujeitos ociosos' como resultado do recebimento da Bolsa Família, bem como da ideia da necessidade de maior vigilância e controle. Desse modo, a Igreja Católica atua como correia de transmissão de versões favoráveis à realização de 'enxugamentos' no número de beneficiários, contribuindo na divulgação do discurso ideológico de que a diminuição dos que acessam o programa se deveria à melhoria geral no desempenho da economia.

\section{REFERÊNCIAS}

ALVES, J. E. D.; CAVENAGHI, S. O Programa Bolsa Família e as taxas de fecundidade no Brasil. In: CAMPELLO, T.; NERI, M. C. (Org.). Programa Bolsa Família: uma década de inclusão e cidadania - Brasília: Ipea, 2013.

BELLO, C. A. Percepções sobre pobreza e bolsa família. In: SINGER, A.; LOUREIRO, I. (Org.). As contradições do lulismo: a que ponto chegamos? 1. ed. São Paulo. Boitempo, 2016.

BRASIL, Ministério do Desenvolvimento Social e Combate à Fome. Programa Bolsa Família. Disponível em: http://www.mds.gov.br/bolsafamilia. Acesso: set./out. 2016. 
BUTLER, J. Vida precária: el poder del duelo y La violência. Buenos Aires: Paidós, 2006.

CARNELOSSI, B. O trabalho do assistente social no Programa Bolsa Família: desafios ao Código de Ética profissional. Serv. Soc. Soc., São Paulo, n. 125, jan./abr., 2016, pp. 124-147. Disponível em: <http://www.scielo.br/pdf/sssoc/ n125/0101-6628-sssoc-125-0124.pdf>. Acesso em: dez. 2017.

CNBB. Carta programática. Edições CNBB, Brasília, 2006.

COHN, A. Cartas ao presidente Lula. Bolsa Família e direitos sociais. Rio de Janeiro: Azougue, 2012.

COSTA, A. B. Discursos sobre os efeitos das políticas públicas de transferência de renda sobre dinâmicas socioeconômicas no Brasil: o caso do Programa Bolsa Família, em Catolé do Rocha/PB. 2018. Dissertação (Mestrado em Desenvolvimento Regional) - Universidade Estadual da Paraíba, 2018.

A vida dos beneficiários do Programa Bolsa Família "relatada" por vozes e falas dos sujeitos invisíveis na região semiárida da Paraíba: a revelação sociológica entre o mito da acomodação e a legitimidade da ascensão social. 2015. 40f. Trabalho de Conclusão de Curso (Graduação em Ciências Agrárias)Universidade Estadual da Paraíba, Catolé do Rocha-PB, 2015. Disponível em: <http://dspace.bc.uepb.edu.br/jspui/handle/123456789/8063>.

FAO. Alimentos e agricultura organização das nações unidas, Edições FAO, Roma, 2014.

FOGUEL, M. N.; BARROS, R. P. The effects of conditional cash transfer programmes on adult labour supply: an empirical analysis using a time-seriescross-section sample of Brazilian municipalities. Estudos Econômicos, São Paulo, v. 40, Junho de 2010, pp. 259-293. Disponível em: <http://www. scielo.br/scielo.php? script $=$ sci_arttext\&pid $=$ S0101-41612010000200001 $>$. Acesso em: dez. 2017.

G1.COM. Portal de Notícias da Globo. Disponível em: http://gazetaweb.globo. com/portal/noticia/2017/07/_37489.php [Acesso em: nov. 2017]

IBGE. Censo Demográfico 2010 - Características Gerais da População. Resultados da amostra. Disponível em: <https://biblioteca.ibge.gov.br/ visualizacao/periodicos/93/cd_2010_caracteristicas_populacao_domicilios. pdf>. Acesso em: dez. 2017. 
IPEA. Sobre a recente queda da desigualdade de renda no Brasil. 2013. Disponível em: <http:// www.ipea.gov.br/sites/0002/publicacoes/ NTquedaatualizada.pdf $>$. Acesso em: ago. 2016.

IVO, A. B. L. Georg Simmel e a "Sociologia da Pobreza". Resenha Temática. Caderno CRH, Salvador, v. 21, n. 52, p. 171-180, jan./abr. 2008.

JORNAL FOLHA DE SÃO PAULO. CNBB diz que Bolsa Família vicia e acomoda beneficiários. Sábado, 18 de novembro de 2006. Disponível em: <http://www1.folha.uol.com.br/fsp/brasil/fc1811200608.htm>. Acesso em: maio 2018].

MARQUIORO, A. K.; FIORENTIN, M. I. S. Utilização da Multimistura como alimento alternativo: a ação da Pastoral da Criança no combate à desnutrição no município de Maripa/PR. Thêma et Scientia, v. 2, n. 2, jul./dez. 2012.

MDSA, Ministério do Desenvolvimento Social. Boletim do Programa Bolsa Família, 2016. Disponível em: <http://www.mds.gov.br/webarquivos/ sala_de_imprensa/boletins/boletim_bolsa_familia/outubro/boletim_bolsa_ familia_27102016.html>. Acesso em: dez. 2017.

MEDEIROS, M.; BRITTO, T.; SOARES, F. Transferência de renda no Brasil. Revista Novos Estudos, v. 79, 2007, pp. 5-21. Disponível em: <http://www. scielo.br/pdf/nec/n79/01.pdf>. Acesso em: dezembro de 2017.

OLIVEIRA, L. F. B. de; SOARES; S. S. D. "Efeito Preguiça" em Programas de Transferência de Renda? In: CAMPELLO, T.; NERI, M. C. (Org.). Programa Bolsa Família: uma década de inclusão e cidadania. Brasília: IPEA, 2013, p. 341-358.

ONU. Relatório sobre Erradicação da Pobreza do Secretário-Geral das Nações Unidas. Dist. General, 2011.

PNUD. Relatório do Desenvolvimento Humano 2014, Technical report, PNUD, 2014.

PROSPERI, L. de O.; FRIAS, L. T. G. de. O Programa Bolsa Família como parte do Programa Brasil Sem Miséria e sua relação com a segurança para a inserção laboral do beneficiário. Qualitas Revista Eletrônica, v.17 n.3 - set.-dez./2016, pp.174-195. Disponível em: < file:// C:/Users/Computador/Downloads/284910203-1-PB.pdf>. Acesso em: mar. 2018.

RAMACCIOT'TI, N. N. Percepções das condicionalidades nos programas de transferência de renda: o caso das beneficiárias do CRAS Morro Nova 
Cintra, Santos, São Paulo. Dissertação defendida no Curso de Mestrado em Ensino de Ciências da Saúde, Universidade Federal de São Paulo, 2014. Disponível em: <http://www2.unifesp.br/centros/cedess/mestrado/baixada_ santista_teses/003_bx_nathalianabor_tese.pdf>. Acesso em: nov. 2017.

RIBAS, R. P.; SOARES, F. V. Is the effect of conditional transfers on labor supply negligible everywhere? 2011. Disponível em: <http://www.iza.org/ conference_files/worldb2011/ribasr6802.pdf>. Acesso em: nov. 2017.

ROCHA, S. Transferências de renda no Brasil: O fim da pobreza? Rio de Janeiro: Elsevier, 2013.

SALES, T. S. O Estado, a pobreza e o Programa Bolsa Família. 1. ed. Curitiba: Editora Prismas, 2015.

SILVA, J. B.; ZIMMERMANN, C.; SOBRINHO, L. D. G.; JUNIOR, E. da S. N.; FERNANDES, M.; COSTA, A. B. Para além de questões eleitorais: o Programa Bolsa Família e seus impactos sobre famílias beneficiárias no semiárido paraibano. Capítulo XVIII, pp. 241-262. In: SOUZA, C. A. de; BARREIROS NETO, J. (Coord.). Democracia BR: o momento político atual. Salvador: Ed. da Faculdade Baiana de Direito, 2016.

SIMMEL, G. Les pauvres. Paris: Presses Universitaires de France, [1905] 1998. Disponível em: <http://www.scielo.br/scielo.php?script=sci_ arttext\&pid=S0103-49792008000100013 > . Acesso em: jan. 2018.

SINGER, A. V. O lulismo em crise (2011-2016): um quebra-cabeça do período Dilma. São Paulo: Companhia das Letras, 2016.

Os sentidos do lulismo: reforma gradual e pacto conservador. 1. ed. São Paulo: Companhia das Letras, 2012.

SOUZA, J. et al. Ralé brasileira: quem é e como vive? Belo Horizonte: Editora da UFMG, 2009.

SOUZA, J. A tolice da inteligência brasileira: ou como o país se deixa manipular pela elite / São Paulo, LeYa, 2015.

SOUZA, J. A radiografia do golpe: entenda como e por que você foi enganado/ Jessé Souza - Rio de Janeiro: LeYa, 2016. 
